\title{
CORRESPONDENCE
}

\section{Don't base Spanish funding on citations}

The Spanish government announced in March that Spain's scientific research quality has overtaken that of Australia and Switzerland (see go.nature.com/ si76qc). It drew this conclusion from a 2011 report by Britain's Royal Society (see go.nature. $\mathrm{com} / \mathrm{q} 8 \mathrm{hmxw}$ ). I question the government's interpretation, given that the Swiss win at least one Nobel prize in science every decade and Spain has not won one for 100 years.

The Royal Society report uses total citation counts as a measure of quality and impact. But citation figures can be misleading, depending on how they are derived. For example, Switzerland and Australia emerge well ahead of Spain when adjustment is made for high-profile, but lowfrequency, breakthroughs among the routine results that dominate citation counting (A. RodríguezNavarro PLoS ONE 6, e20510; 2011).

The Spanish government's apparent misinterpretation has led to a reduction in tenure for young scientists, among other funding cuts justified on the grounds that Spain has too many researchers. The government should look instead to the excessive number of university professors, who are not always picked for their research record.

Spain's scientific societies should oppose this misguided research policy if the country's science is to improve.

Alonso Rodríguez-Navarro Polytechnic University of Madrid, Spain.alonso.rodriguez@upm.es

\section{Is China producing too many PhDs?}

China produced an estimated $117,000 \mathrm{PhD}$ graduates in $2010-$ more than any other nation, and a tenfold increase on 1999 figures (see go.nature.com/xbdqm9; in Chinese). It looks set to fulfil the government's goal of becoming a leader in higher education except that the quantity of $\mathrm{PhDs}$ awarded has diluted their quality.

This boom has overburdened the country's education infrastructure. Standards are compromised by a lack of proper quality control and of elimination mechanisms for trainee $\mathrm{PhDs}$ (Nature 472, 276-279; 2011).

Employment opportunities for home-grown $\mathrm{PhDs}$ are dwindling. Universities and research institutes want to recruit Chinese people with foreign PhDs, and corporations prefer graduates with a master's degree because they cost less.

Given the global excess of $\mathrm{PhDs}$ (Nature 472, 280-282; 2011), China must remodel its education system and introduce rigorous elimination mechanisms in $\mathrm{PhD}$ training.

Zhu Liu, Yong Geng Institute of Applied Ecology, Chinese Academy of Sciences, Shenyang, China.liuzhu@iae.ac.cn

\section{Reward research that informs policy}

We agree that science policy can and should encourage research programmes that deliver public values - the core aspirations that motivate and justify public spending on science (Nature 473, 123-124; 2011).

The public expects climate research to generate useful, reliable knowledge. This is more likely when programmes engage with the policy and public context in which they are embedded. Such engagement is not easy, or popular. It demands creativity, resources and collaboration with diverse communities.

Scientists working on important societal problems are usually subject to the same metrics of success as theoretical physicists and mathematicians - peer-reviewed articles. Nevertheless, some scientists and organizations generate useful information for policy-makers and for public benefit. More must be done to recognize and reward their contribution, and encourage others to follow their example.

Thus, it is not a question of whether the United States has enough institutional capacity, as you ask, but how it can develop appropriate kinds of institutions. Pouring money into the same institutional framework is unlikely to bring climate research into line with society's expectations.

Ryan Meyer, Peat Leith

University of Tasmania,

Australia.ryan@ryanmeyer.org

\section{Promoting science careers in Brazil}

The prestigious State University of Campinas, which accounts for almost $15 \%$ of Brazil's output of scientific research papers, has been running a successful programme since 2003 that has similar goals to Scientific American's ' 1,000 Scientists in 1,000 Days' initiative (Nature 473, 123; 2011).

'Vocations in Science and the Arts' helps public high schools in the city. Students spend a month in one of the university's research laboratories, learning how to conduct a simple research project and how to interpret their findings. They then present these at a university 'congress'. They feel like scientists from start to finish, and get a sense of the highs and lows of research work.

Our molecular-genetics lab has so far helped 18 students under this programme, of whom at least one-third are intending to pursue a career in biology.

Lucas Leite Cunha, Laura

Sterian Ward, State University of Campinas, Brazil.

lucasleitecunha@gmail.com

\section{Community is key to REDD success}

As workers with indigenous communities in the

Solomon Islands, we believe a fundamental issue must be addressed if REDD (the United Nations' Collaborative Programme on reducing emissions from deforestation and forest degradation) is to respect the rights of indigenous peoples meaningfully (Nature 472, 390; 2011).

Indigenous landowners have set up the Tetepare Descendants' Association (TDA) to protect the large, uninhabited island of Tetepare, an important carbon sink. The association has successfully countered threats posed by timber companies contracting with individuals across the Solomons for timber rights that belong to clans or tribes.

Such community organization is essential for engagement with REDD. But, ironically, it has become harder for the TDA to certify its carbon under the Voluntary Carbon Standard (VCS), a carboncredit verification programme. This is partly because the TDA's short-term success has made it more complicated to prove that a VCS project would result in additional carbon sequestration.

The existence of a communitybased organization such as the TDA should not hinder participation in REDD. Community commitment to preventing deforestation is essential if UN programmes are to succeed.

Unless REDD provides the incentive for legitimate community-governance structures, indigenous rights will not be respected.

Brian Weeks New York, USA. bcweeks@gmail.com Christopher Filardi Missoula, Montana, USA. 